\title{
Quantitative Precipitation Estimation over Ocean Using Bayesian Approach from Microwave Observations during the Typhoon Season
}

\author{
Jen-Chi Hu, ${ }^{1, *}$, Wann-Jin Chen ${ }^{2}$, J. Christine Chiu ${ }^{3,4}$, Jiang-Liang Wang ${ }^{2}$, and Gin-Rong Liu ${ }^{5}$ \\ ${ }^{1}$ School of Defense Science, Chung Cheng Institute of Technology, National Defense University, Ta-Hsi, Tao-Yuan, Taiwan, ROC \\ ${ }^{2}$ Department of Environmental Information and Engineering, Chung Cheng Institute of Technology, National Defense University, \\ Ta-Hsi, Tao-Yuan, Taiwan, ROC \\ ${ }^{3}$ University of Maryland, Baltimore County, Baltimore, Maryland, USA \\ ${ }^{4}$ NASA/Goddard Space Flight Center, Greenbelt, Maryland, USA \\ ${ }^{5}$ Center for Space and Remote Sensing Research, National Central University, Jhongli, Taiwan, ROC
}

Received 25 June 2008, accepted 17 December 2008

\begin{abstract}
We have developed a new Bayesian approach to retrieve oceanic rain rate from the Tropical Rainfall Measuring Mission (TRMM) Microwave Imager (TMI), with an emphasis on typhoon cases in the West Pacific. Retrieved rain rates are validated with measurements of rain gauges located on Japanese islands. To demonstrate improvement, retrievals are also compared with those from the TRMM/Precipitation Radar (PR), the Goddard Profiling Algorithm (GPROF), and a multi-channel linear regression statistical method (MLRS). We have found that qualitatively, all methods retrieved similar horizontal distributions in terms of locations of eyes and rain bands of typhoons. Quantitatively, our new Bayesian retrievals have the best linearity and the smallest root mean square (RMS) error against rain gauge data for 16 typhoon overpasses in 2004. The correlation coefficient and RMS of our retrievals are 0.95 and $\sim 2 \mathrm{~mm} \mathrm{hr}^{-1}$, respectively. In particular, at heavy rain rates, our Bayesian retrievals outperform those retrieved from GPROF and MLRS. Overall, the new Bayesian approach accurately retrieves surface rain rate for typhoon cases. Accurate rain rate estimates from this method can be assimilated in models to improve forecast and prevent potential damages in Taiwan during typhoon seasons.
\end{abstract}

Key words: Bayesian, Rain rate, Typhoon, TRMM, GPROF

Citation: Hu, J. C., W. J. Chen, J. C. Chiu, J. L. Wang, and G. R. Liu, 2009: Quantitative precipitation estimation over ocean using Bayesian approach from microwave observations during the typhoon season. Terr. Atmos. Ocean. Sci., 20, 817-832, doi: 10.3319/TAO.2008.12.17.01(A)

\section{INTRODUCTION}

Precipitation measurements are an essential component for understanding the variability and feedback of surfaceatmospheric processes in water and energy cycles (McCabe et al. 2008). Assimilations of precipitation also demonstrated significant improvement in regional and climate modeling (Treadon 1996; Hou et al. 2001; Krishnamurti et al. 2001; Hou et al. 2004; Atlas et al. 2005). Global precipitation is observed from various platforms, including rain gauges, surface radars, and spaceborne visible, infrared, microwave, and radar sensors (Nesbitt et al. 2004). Among them, satellite microwave observations are now widely used to retrieve surface rainfall because of their ability to penetrate clouds (Adler et al. 2001).

\footnotetext{
* Corresponding author

E-mail:g970101@gmail.com
}

The Tropical Rainfall Measuring Mission (TRMM) satellite, launched in 1997, has successfully provided passive microwave as well as active radar observations in the tropics. The TRMM Microwave Imager (TMI) measures dual polarizations at frequencies ranging from 10 to $85 \mathrm{GHz}$, while the Precipitation Radar (PR) is operated at $13.8 \mathrm{GHz}$ (Kummerow et al. 1998). Tremendous efforts were made in both development and validation of retrieval methods from TMI and PR data (Benedetti et al. 2005).

A number of rain rate $(\mathrm{RR})$ retrieval methods were developed based on the Bayes' theorem methods (Evans et al. 1995; Olson et al. 1996; Marzano et al. 2002; Di Michele et al. 2005; Chiu and Petty 2006; Grecu and Olson 2006; Olson et al. 2006). The theorem describes that for a given set of observations the posterior probability density function (PDF) of parameters to be retrieved can be computed from the pro- 
duct of the conditional and the prior PDF, as shown in the following formula:

$$
f(R \mid \mathrm{P}) \propto f(\mathrm{P} \mid R) f(R)
$$

In this formula, $R$ is the RR to be retrieved, and $P$ represents passive microwave observations. $f(R \mid \mathrm{P})$ is the posterior PDF describing RR probability at given observations. $f(\mathrm{P} \mid R)$ is the conditional PDF that defines the dependency of observations on $\mathrm{RR}$, and $f(R)$ is our prior knowledge of RR. This formula provides a theoretical framework that optimally combines prior knowledge with new evidence (e.g., observations).

The Bayes' theorem has been applied to retrieval methods in different ways. First, training databases are different. One can characterize the prior and conditional PDFs using cloud-radiative simulations or match-up datasets. The advantage of the use of simulations is the ability to retrieve hydrometeor vertical profiles of rain clouds. However, retrieval performance strongly relies on the representativeness and variety of model simulations (Kummerow et al. 2000; Masunaga et al. 2002). On the other hand, match-up datasets could include calibrated RR measurements, and thus retrievals are not affected by simulation accuracy. However, large samples are typically required to meet statistical significance. Second, approaches to construct probability density functions are different. One can retrieve precipitation properties by either selecting cloud profiles in which simulated microwave signatures are closed to observations, or using explicit functions to fully describe the prior and conditional PDFs. The use of explicit functions makes it possible to derive the complete posterior PDF of RR, which is important for assimilation purposes.

Validating retrieved RR over the ocean can be difficult. Up to now, validations are often conducted against retrievals either from PR or from other TMI algorithms. However, a number of studies demonstrated that RRs from PR standard products were systematically lower than measurements from buoy rain gauges (Serra and McPhaden 2003; Bowman 2005; DeMoss and Bowman 2007). As a result, intercomparison with other retrievals only ascertains whether the algorithm performance is comparable with others. Direct measurements from rain gauges are still needed in retrieval validation.

This paper demonstrates a new Bayesian approach for RR retrievals from TMI observations, with an emphasis on typhoon cases in the West Pacific. Note that most algorithms aim to provide unbiased global precipitation estimates, and thus various types of precipitation systems in different climate regimes are included to ensure the representativeness of training databases. However, this type of algorithms might not work well for heavy rain events. For examples, comparison between version 5 TMI standard retrieval product (2A12) and buoy rain gauge readings showed that the high bias of TMI increased with increasing RRs (Nesbitt et al.
2004). Because the ultimate goal of this study is to improve predictions of typhoon tracks and landfall in the surrounding area of Taiwan, we develop a new method to accurately estimate surface rainfall particularly for typhoons.

As previously mentioned, ideally, oceanic RR retrievals should be validated against buoy rain gauge data. Unfortunately, there is no buoy rain gauge network around Taiwan. Therefore, we evaluate our retrievals mainly against rain gauges located on Japanese islands in the West Pacific. We are aware that data from rain gauges on islands might be affected by local topography and land surface heating. To minimize those effects, we carefully selected rain gauges and examined precipitation homogeneity with TRMM visible and infrared observations.

This paper is organized as follows. In section 2, we briefly review key features of TMI and PR, as well as the physical relationship between microwave observations and RR. In section 3, we detail the basis of our retrieval method, including cloud-radiative simulations used to construct explicit functions of the conditional PDFs. In section 4, we validate retrieval against rain gauge data and retrievals from two other benchmark algorithms. Conclusions are given in section 5 .

\section{SATELLITE OBSERVATIONS}

\subsection{TRMM/Microwave Imager (TMI)}

The TRMM satellite was launched in 1997 and positioned in an orbit of $350 \mathrm{~km}$. To extend TRMM's mission life, the operating orbit was boosted to $403 \mathrm{~km}$ in August 2001. The TMI scans the earth conically with a swath of $760 \mathrm{~km}$ (pre-boost) and $878 \mathrm{~km}$ (post-boost). The incident angle is about $52.8^{\circ}$. The TMI measures dual-polarized brightness temperatures (TBs) at 10.65, 19.35, 37.0, and $85.5 \mathrm{GHz}$, except $21.3 \mathrm{GHz}$ with vertical polarization only. The field-of-view (FOV) of TMI depends on frequencies, and is slightly larger in the post-boost period than in the preboost period. For the purpose of development and validation of our retrieval method, brightness temperatures (version 6) for all channels are interpolated to $10 \times 10 \mathrm{~km}$ grid points. After interpolations, the vertically polarized TBs for the aforementioned TMI channels are denoted as $\mathrm{TB}_{10 \mathrm{v}}, \mathrm{TB}_{19 \mathrm{~V}}$, $\mathrm{TB}_{21 \mathrm{~V}}, \mathrm{~TB}_{37 \mathrm{~V}}$, and $\mathrm{TB}_{85 \mathrm{~V}}$, and replaced the $\mathrm{V}$ with $\mathrm{H}$ for horizontal polarizations. Detailed descriptions of TMI can be found in Kummerow et al. (1998).

To illustrate characteristics of microwave observation, we simulated the response of microwave signatures to $R R$ using the TMI channels. Similar to results in Petty (2001) for $\mathrm{SSM} / \mathrm{I}$ channels, our simulations (Fig. 1a) show non-linear, non-monotonic relationships between microwave brightness temperature and RR. At lighter RRs, TB increases with RR due to emission. In contrast, at higher RRs, TB decreases with RR due to scattering. The depression in TB due to scattering is more substantial at higher frequencies. In addition, 

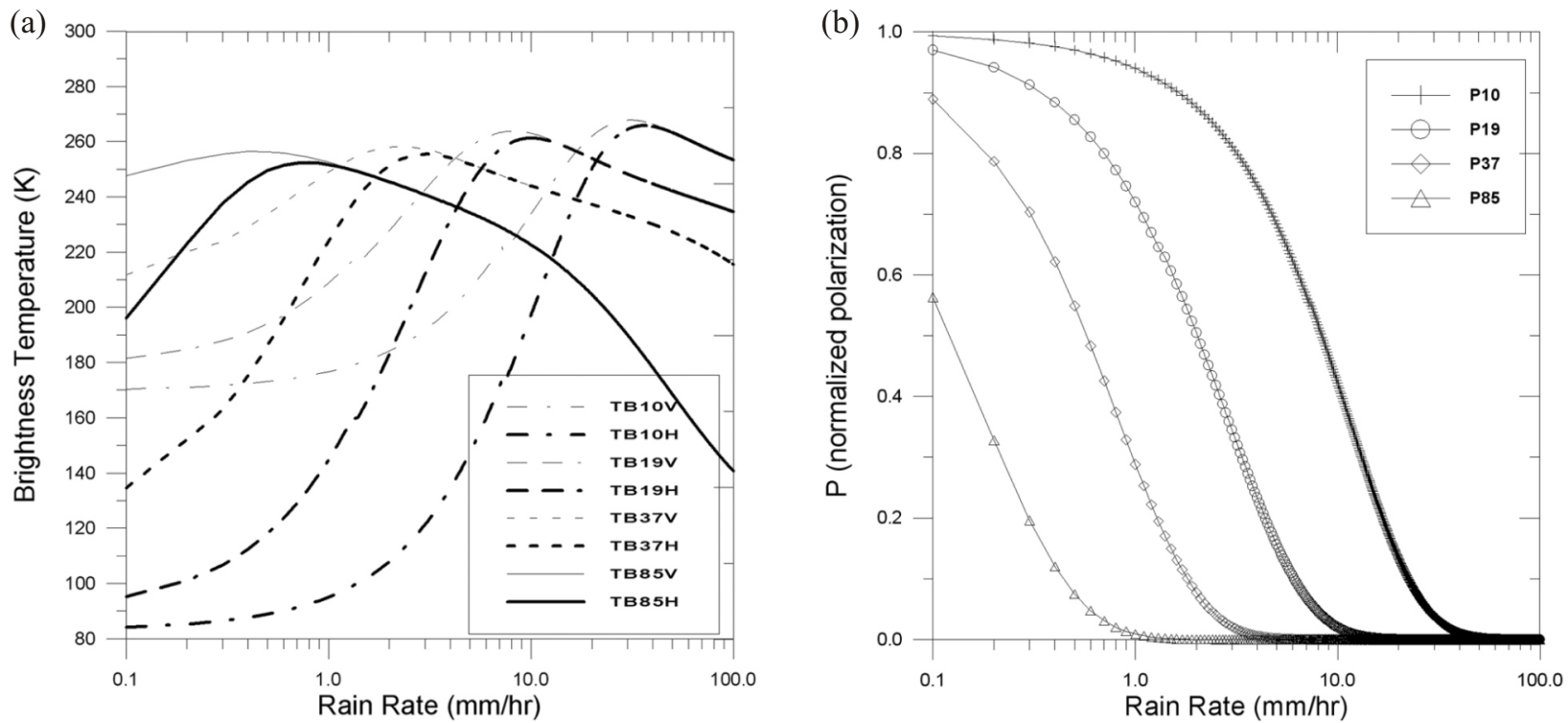

Fig. 1. (a) Idealized TBs versus surface rain rate over ocean, and (b) the relationship between corresponding attenuation $P$ index and rain rate for TMI channels of $10.65,19.35,37.0$, and $85.0 \mathrm{GHz}$.

due to the non-polarized emission of rain clouds, polarization difference becomes smaller with increasing RR. Note that simulations in Fig. 1 were based on a simple rain cloud, similar to Wilheit et al. (1977). Simulated brightness temperatures could vary significantly with many factors, including sea surface temperature, surface wind speed, water vapor, as well as the assumed density, size distribution, and vertical distribution of hydrometeors.

Because microwave brightness temperature shows nonmonotonic dependency on RR, Petty (1994) proposed an attenuation index $(\mathrm{P})$ as the observed variable to reduce retrieval ambiguity. The $P$ index is defined as:

$P=\frac{T_{v}-T_{h}}{T_{v, o}-T_{h, o}}$

where $T_{v}$ and $T_{h}$ are vertically and horizontally polarized TB; $T_{v, o}$ and $T_{h, o}$ are the TBs in the clear sky (i.e., background brightness temperatures). For simulations, background brightness temperatures can be calculated by simply setting all hydrometeors to be zero. For real-world applications, brightness temperatures can be modeled using empirical regression equations that account for column water vapor, surface wind speed, and sea surface temperature (Chiu and Petty 2006).

Ideally, $P$ will be in the range between 0 and 1 , where 1 corresponds to a cloud-free situation, and values approaching 0 correspond to a very opaque atmospheric condition associated with heavy precipitation. The attenuation index $P$ is favorable over direct brightness temperature because $P$ is not sensitive to the background variability, and has a mo- notonic dependency on RR. This monotonic relationship between $P$ and RR is shown in Fig. 1b, corresponding to the same precipitation system used in Fig. 1a. Figure $1 \mathrm{~b}$ also shows that the attenuation indices approach 0 (i.e., saturated) at smaller RR for higher frequencies. For example, the attenuation index at $85 \mathrm{GHz}$ is saturated at $1 \mathrm{~mm} \mathrm{hr}^{-1}$, while the attenuation index at $10.65 \mathrm{GHz}$ is not saturated until around $30 \mathrm{~mm} \mathrm{hr}^{-1}$. Because this paper focuses on typhoons that are typically associated with heavy RR, $P$ at $85 \mathrm{GHz}$ cannot provide enough information on RR in these environments. Therefore, only three attenuation indices at 10.65 , 19.35, and $37.0 \mathrm{GHz}$ are used as observation variables and denoted as a $\boldsymbol{P}$ vector, $\left(P_{10}, P_{19}, P_{37}\right)$ in this study.

\subsection{TRMM/Precipitation Radar (PR)}

The TRMM/PR is an electronic scanning radar operated at $13.8 \mathrm{GHz}$, measuring 3D precipitation distributions over both land and ocean surfaces (Kummerow et al. 1998). The PR scans $17^{\circ}$ to either side of nadir at an interval of $0.35^{\circ}$, giving a swath width of $215 \mathrm{~km}$ (pre-boost) and $247 \mathrm{~km}$ (post-boost). The horizontal footprint at nadir is from $4.3 \mathrm{~km}$ (pre-boost) to $5 \mathrm{~km}$ (post-boost), and the vertical resolution is $250 \mathrm{~m}$. The minimum detectable threshold of PR reflectivity is about $17 \mathrm{dBZ}$ without attenuation, corresponding to a rain rate of $0.5-0.7 \mathrm{~mm} \mathrm{hr}^{-1}$. The TRMM/PR standard product (2A25) contains vertical profiles of RR retrieved through the Z-R relations (Iguchi et al. 2000). In this study, we used near-surface RRs in 2A25 and interpolated them to $10 \times 10 \mathrm{~km}$ grid points in order to match TMI data. For convenience, the interpolated near-surface $R R$ is referred as $P R$ RR hereafter. Note that according to Demoss and Bowman 
(2007), PR-retrieved RR has a low bias relative to rain gauge data, but the change in bias from pre- to post-boost period is not significant.

\section{RETRIEVAL ALGORITHM}

As previously mentioned, the posterior RR distribution is determined by the prior RR PDF and the conditional PDF that describes physical relationships between RR and observed variables. We referred to this physical relationship as the RR-P relationship hereafter, because our retrieval method use $P$ index as the observed variable. To characterize the prior PDF, it is important to have calibrated RR measurements and a significant amount of data. Therefore, we used PR data to specify the prior RR distribution. For the conditional PDF, the RR-P relationship can be specified by two approaches. One is to derive the relationship from PR-TMI match-up data; the other is from model simulations. We attempted to match PR and TMI data for typhoon cases, but found that the sample size was small. As a result, we specified our conditional PDF using simulations from the Goddard Cumulus Ensemble (GCE) model (Tao and Simpson 1989, 1993; Tao et al. 2003) and a 3D fast radiative transfer model (Liu 1998, 2004). Details in model simulations are given next.

\subsection{Simulations from Cloud-Resolving and Radiative Transfer Models}

We used the GCE model to generate 5-day simulations for the Kwajalein Experiment (KWAJEX) field campaign during 7 - 12 August 1999. The equations that govern the cloud-scale motion (wind) in the GCE model are elastic. The cloud microphysics parameterization is based on a 5-category scheme, including cloud water, cloud ice, rain, snow and graupel (Lin et al. 1983; Rutledge and Hobbs 1984). Drop size distributions for rain, snow, and graupel followed the Marshall-Palmer distribution (Marshall and Palmer 1948). The densities for snow and graupel were assumed 0.1 and $0.4 \mathrm{~g} \mathrm{~cm}^{-3}$, respectively. The horizontal domain was 512 $\times 512 \mathrm{~km}$ with a horizontal grid resolution of $2 \mathrm{~km}$. The vertical domain contained 32 layers with a varying resolution from $143 \mathrm{~m}$ in the boundary layer to $1164 \mathrm{~m}$ near the model top. The time step was 12 seconds.

To simulate microwave brightness temperatures, the outputs of GCE model for KWAJEX were then used as input to a 3D radiative transfer model developed by Liu (1998 2004). The model assumed sea surface temperatures of $300 \mathrm{~K}$. Brightness temperatures were simulated from 4-stream calculations. We compared TBs to those simulated from 32 -stream calculations, and found that the error from using 4 streams is generally less than $1 \mathrm{~K}$. The calculated TBs were then averaged to a $10 \mathrm{~km}$ resolution for developing our retrieval method.
Note that the weather system simulated for KWAJEX was a squall line. While our emphasis is placed on RR retrieval for typhoons, it is natural to characterize the RR-P relationship using typhoon simulations instead of squall line systems. The main reason for the use of Kwajalein squall line simulations is because of the concern about the large scale forcing introduced to the cloud-resolving model. The initial forcing is crucial for the success of simulations. During the KWAJEX, better initial dynamic fields were provided for the GCE model because soundings were launched typically every 6 hours on 6 islands and the NOAA Ship Brown. In addition, a number of studies have reported their evaluations of the KWAJEX simulations (Shie et al. 2003; Seo et al. 2007; Zeng et al. 2008). In general, it remains difficult for cloud-resolving models to produce horizontal and vertical precipitation distributions similar to observations, but the statistical characteristics of cloud microphysical variables from simulations are proven representative.

To better understand the representativeness of our simulations from the cloud-resolving model and radiative transfer model, we compare simulated brightness temperatures with those observed from TMI. By examining horizontal distributions of simulated and observed $\mathrm{TB}_{37 \mathrm{~V}}$ for one of the output time periods (as shown in Fig. 2), we found that there was no great similarity between the two. This confirms that we cannot compare simulations with satellite observations on a point-to-point basis, but rather a statistical basis is required. We then further examined occurrence histograms of simulated and observed brightness temperatures for all channels. The occurrence histograms were calculated by binning brightness temperatures with an interval of $10 \mathrm{~K}$, as shown in Fig. 3. Because our retrieval method uses information from $10.65,19.35$, and $37 \mathrm{GHz}$, the following comparisons are focused on these three channels only.

Figures $3 \mathrm{a}-\mathrm{b}$ show that simulations have the same modes of occurrence histograms as TMI observations at $10.65 \mathrm{GHz}$. The modes are located at $170-180 \mathrm{~K}$ and 90 $100 \mathrm{~K}$ for $\mathrm{TB}_{10 \mathrm{~V}}$ and $\mathrm{TB}_{10 \mathrm{H}}$, respectively. Recall that emission dominates at $10.65 \mathrm{GHz}$, and thus brightness temperature increases with rain rate (as discussed in section 2 and Fig. 1). In other words, low brightness temperatures in this frequency correspond to areas associated with either no rain or very light rain rate. Therefore, the consistencies between simulations and observations in the mode locations and the lowest value ranges indicate that the set up of the background atmospheric status in the radiative transfer model is appropriate. However, we notice that for both vertically and horizontally polarized status, simulations show more points associated with higher TBs than observations. In general, a higher brightness temperature corresponds to a heavier rain rate unless scattering becomes significant. Therefore, the excess in the amount of points with higher TBs implies that model outputs may generate more areas with higher RRs, which are not seen in actual observations. 

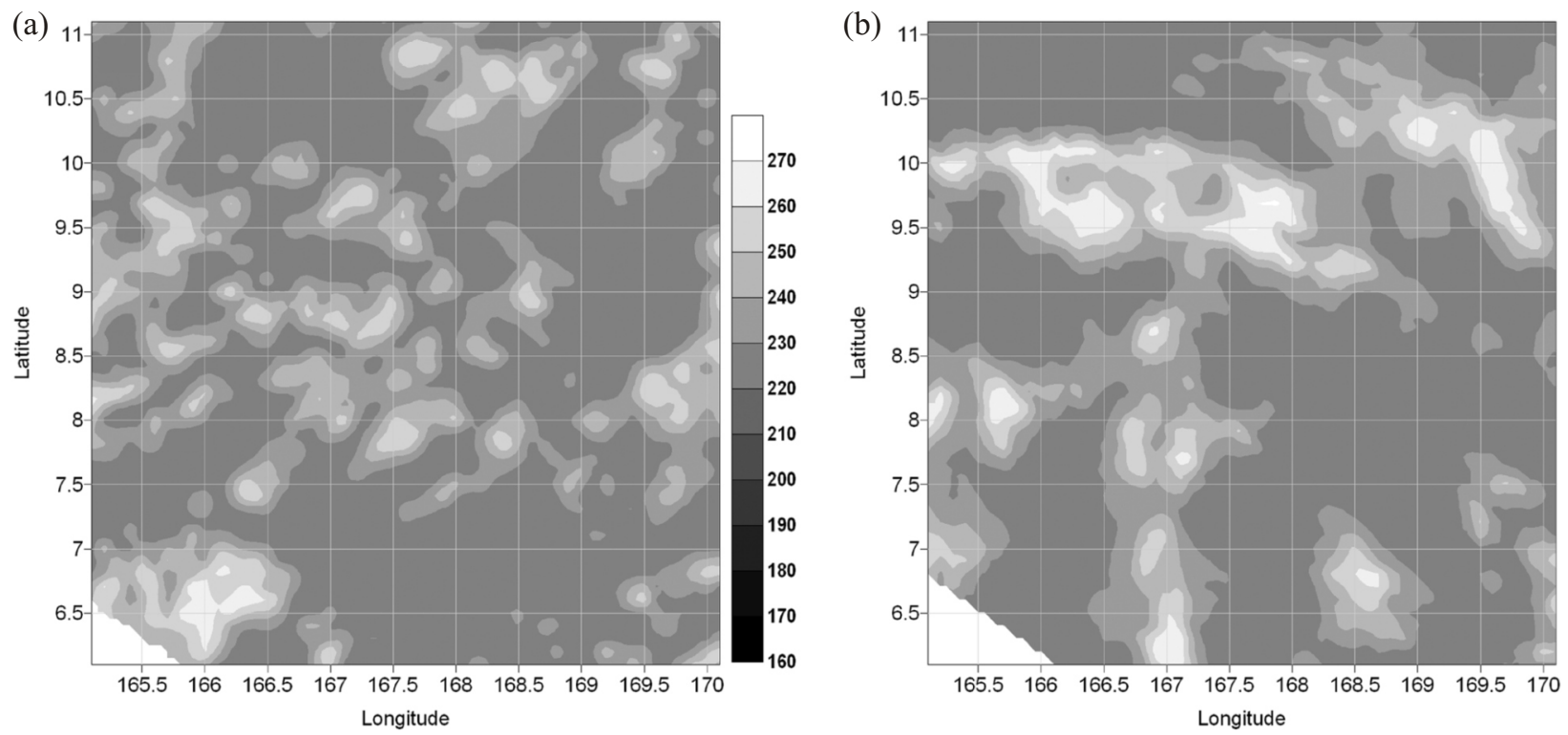

Fig. 2. Vertically polarized brightness temperatures at $37 \mathrm{GHz}$ from (a) model simulations and (b) TRMM/TMI measurements for the Kwajalein Experiment on 10 August 1999. Simulations are based on outputs of the cloud-resolving model at 1300 UTC, while TMI observations were taken at 1256 UTC.
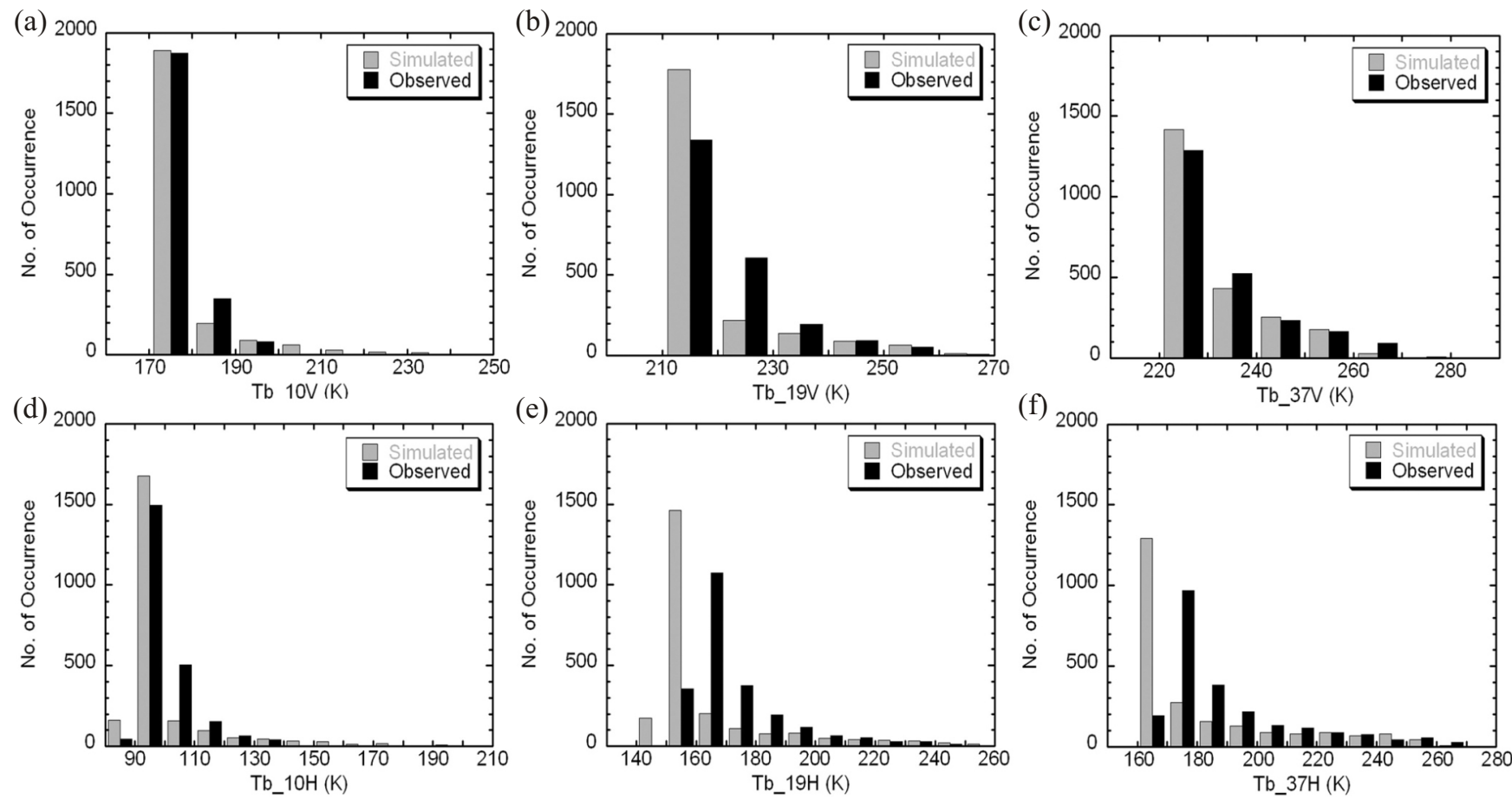

Fig. 3. Histograms of: (a) $\mathrm{TB}_{10 \mathrm{~V}}$, (b) $\mathrm{TB}_{19 \mathrm{~V}}$, (c) $\mathrm{TB}_{37 \mathrm{~V}}$, (d) $\mathrm{TB}_{10 \mathrm{H}}$, (e) $\mathrm{TB}_{19 \mathrm{H}}$, and (f) $\mathrm{TB}_{37 \mathrm{H}}$, from simulations (grey) and TMI observations (black). The bin size of the histograms is $10 \mathrm{~K}$.

Figures $3 c-d$ show that the modes of the occurrence histograms for simulated and observed $\mathrm{TB}_{19 \mathrm{~V}}$ values are the same, but different by $\sim 10 \mathrm{~K}$ for $\mathrm{TB}_{19 \mathrm{H}}$. Similarly, the mode locations for $\mathrm{TB}_{37 \mathrm{H}}$ also have a shift of $10 \mathrm{~K}$ between simulations and observations (Figs. 3e, f). The shift in the mode lo- cations for horizontally polarized TBs may be attributed to the following factors. First, the observations might have more data points with non-precipitating clouds or very light rain rates. As shown in Fig. 1a, a small increase of RR in the light rain regime enhances TBs significantly. The rate of en- 
hancement in TB is greater for the higher frequency and the horizontally polarized status than that for the lower frequency and the vertically polarized. It explains why the shift in the mode locations is shown in $\mathrm{TB}_{19 \mathrm{H}}$ and $\mathrm{TB}_{37 \mathrm{H}}$, but not in $\mathrm{TB}_{19 \mathrm{v}}$ and $\mathrm{TB}_{37 \mathrm{v}}$.

Second, Zeng et al. (2008) reported that the precipitable water in simulations was smaller than that in observations by $\sim 10 \mathrm{~mm}$. This dry bias of simulations has a negligible impact on TB at $10.65 \mathrm{GHz}$. However, the bias alone could reduce simulated $\mathrm{TB}_{19 \mathrm{~V}}$ and $\mathrm{TB}_{37 \mathrm{~V}}$ by $\sim 4 \mathrm{~K}$, and $\mathrm{TB}_{19 \mathrm{H}}$ and $\mathrm{TB}_{37 \mathrm{H}}$ by $\sim 7 \mathrm{~K}$, causing the mode shift of simulations toward the lower values. Note that the errors due to water vapor uncertainty will be greatly cancelled out in calculations of $\boldsymbol{P}$ values. As a result, our method is not sensitive to this type of error, as shown by histograms of simulated and observed $\boldsymbol{P}$ indices (Fig. 4).

As expected, Fig. 4 shows that in all channels, most of the rain-free grid points in simulations have $P$ values of 1 (an ideal value, in the bin of $1-1.1$ ), and some are slightly less than 1 . The majority of the observed $P$ values for rain-free points are also around 1 , while some are slightly greater than 1 due to instrument noise and errors in estimation of background brightness temperatures. Because our interest is in rainy areas, the difference in $P$ values close to 1 is not a con- cern for our retrieval method.

In the $P$ range between 0 and 0.9 that corresponds to rainy areas, we see remarkable agreement between simulations and observations at 19.35 and $37 \mathrm{GHz}$, except at $10.65 \mathrm{GHz}$. As previously discussed, compared to observations, simulations have a larger amount of grid points with higher rain rates, resulting in an excess of low simulated $P_{10}$ values. This difference is not necessarily a defect for our retrieval method. In fact, the wider range of $P_{10}$ in simulations allows us to better characterize conditional PDFs, which is not easily sampled and achieved using actual observations, as confirmed in Fig. 5.

Figure 5 shows scatter plots of $P_{10}, P_{19}$, and $P_{37}$ that are a crucial indicator to evaluate whether simulations well represent the joint PDFs of $P_{10}, P_{19}$, and $P_{37}$. Figure 5a demonstrates that the simulations agree well with observations in representing the highly non-linear relationship between $P_{19}$ and $P_{37}$. Figure $5 \mathrm{~b}$ also shows that the majority of observations overlap well with simulations. However, apparently, the use of observations is insufficient to represent heavy rain events because of the lack of samples with lower $P_{10}$ values.

In summary, we are confident that our cloud-radiative simulations can be used to properly characterize RR-P relationships. The final simulations contain $8 \times 10^{4}$ samples,
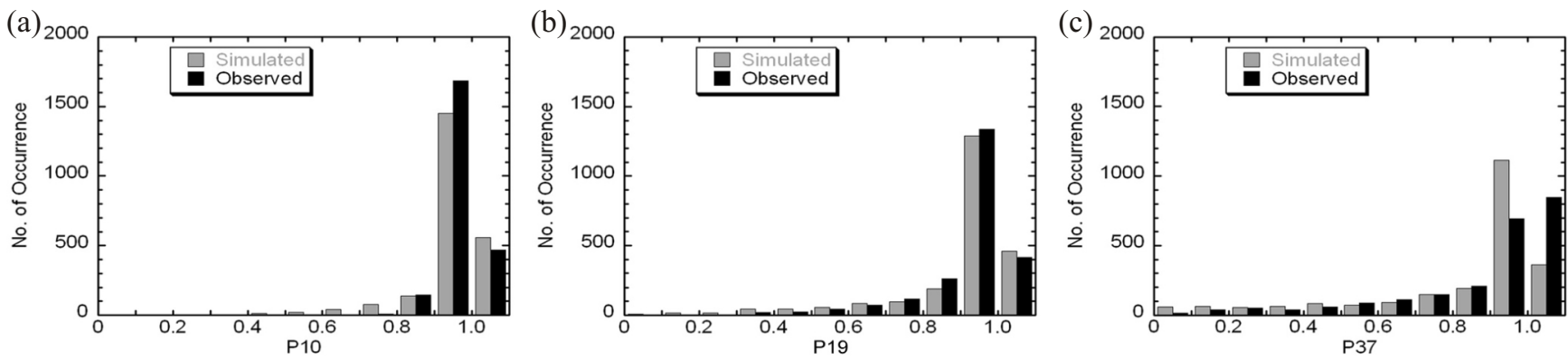

Fig. 4. Histograms of attenuation index $P_{10}, P_{19}$, and $P_{37}$ calculated from simulations (grey) and TMI observations (black).

(a)

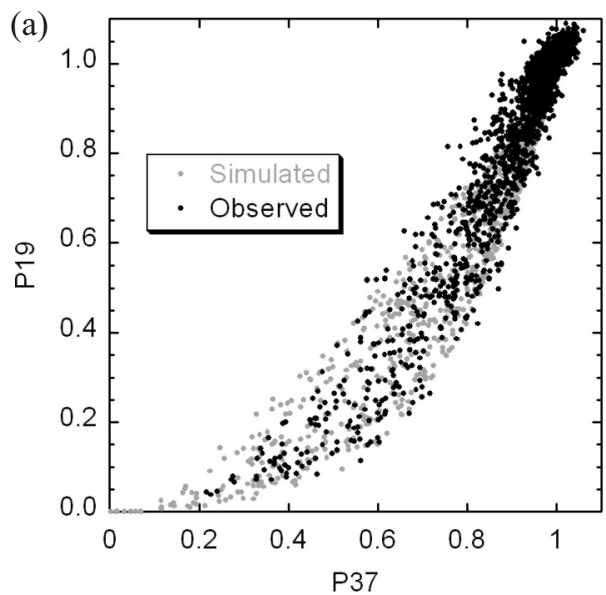

(b)

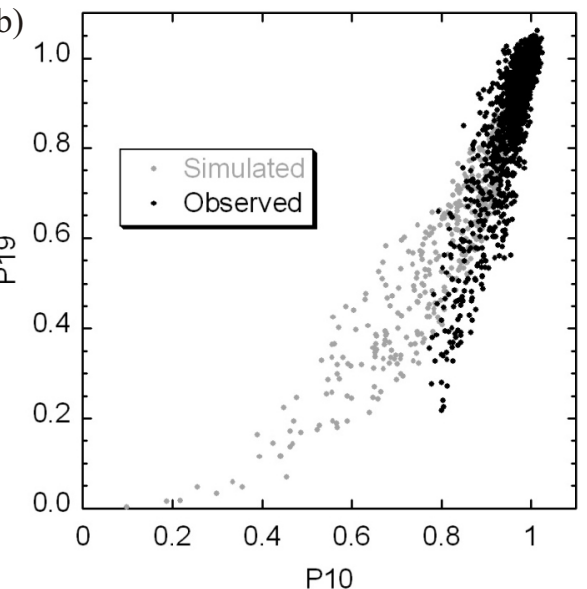

Fig. 5. Scatter plots of (a) $P_{19}$ vs. $P_{37}$ and (b) $P_{19}$ vs. $P_{10}$ from simulations (grey dots) and observations (black dots). 
with a rain rate range between 0.01 and $85 \mathrm{~mm} \mathrm{hr}^{-1}$.

\subsection{Characterizations of the Conditional and Prior PDF}

The relationship between $\boldsymbol{P}$ vector and RR can be approximated by:

$f(\mathrm{P} \mid R)=f\left(P_{37} \mid R\right) f\left(P_{19} \mid P_{37}, R\right) f\left(P_{10} \mid P_{19}, P_{37}, R\right)$

where $f\left(p_{37} \mid R\right)$ is the conditional PDF of $P_{37}$ at a given $R$; $f\left(p_{19} \mid P_{37}, R\right)$ is the conditional PDF of $P_{19}$ at given $P_{37}$ and $R$; and $f\left(P_{10} \mid P_{19}, P_{37}, R\right)$ is the conditional PDF of $P_{10}$ at given $P_{19}, P_{37}$, and $R$. These PDFs are further parameterized as:

$f\left(P_{37} \mid R\right) \propto P_{37}\left(1-P_{37}\right) \exp \left[-\frac{1}{2 \sigma_{3}^{2}}\left(P_{37}-\mu_{3}\right)^{2}\right]$

$f\left(P_{19} \mid P_{37}, R\right) \propto P_{19}\left(1-P_{19}\right) \exp \left[-\frac{1}{2 \sigma_{2}^{2}}\left(P_{19}-\mu_{2}\right)^{2}\right]$

$f\left(P_{10} \mid P_{19}, P_{37}, R\right) \propto P_{10}\left(1-P_{10}\right) \exp \left[-\frac{1}{2 \sigma_{1}{ }^{2}}\left(P_{10}-\mu_{1}\right)^{2}\right](6)$

where $\mu_{i}$ and $\sigma_{i}(i=1,2,3)$ are determined by fitting the aforementioned model simulations. Note that parameters $\mu_{i}$ and $\sigma_{i}$ are not constants, but rather complicated functions. For example, $\mu_{3}$ and $\sigma_{3}$ are a function of $R$, showing the dependency of $P_{37}$ on $R$. Similarly, parameters $\mu_{2}$ and $\sigma_{2}$ are a function $P_{37}$ and $R$, and parameters $\mu_{1}$ and $\sigma_{1}$ are a function $P_{19}, P_{37}$, and $R$. The complexity in parameters $\mu_{i}$ and $\sigma_{i}$ becomes greater from Eq. (4) to (6), because the PDF is conditioned at more variables in Eq. (6). In addition, distributions of Eq. (4) to (6) are not necessarily bell-shaped. More details can be found in Chiu (2003).

Chiu and Petty (2006) pointed out that the specification of the prior RR distribution is crucial for the success of a Bayesian algorithm. However, once the prior is properly characterized, retrieved $R R$ is not sensitive to small variations of the prior PDF. Therefore, we used the same prior distribution as that in their study, and briefly review their method as follows.

Surface rain rate distributions have been commonly parameterized by lognormal functions (Kedem et al. 1990; Sauvageot 1994; Nzeukou and Sauvageot 2002). Therefore, we used a lognormal function to characterize the prior distribution rain rate, defined as:

$\log N(R \mid \mu, \sigma)=$

$(2 \pi)^{-1 / 2}(R \sigma)^{-1 / 2} \exp \left[-\frac{1}{2 \sigma^{2}}(\ln R-\mu)^{2}\right], R>0$ where $R, \mu$, and $\sigma$ are the rain rate, the mean and standard deviation, respectively, all in unit of $\mathrm{mm} \mathrm{hr}^{-1}$. By fitting 4-month PR data in 1998, parameters $\mu$ and $\sigma$ were determined as -2.8 and 2.0 , respectively. It is worth noting that the lognormal distribution is not the only choice for characterizing PR-observed surface RR. Cho et al. (2004) has found that a Gamma distribution is also proper to model PR RRs.

\subsection{Summary of the New RR Retrieval Algorithm}

A flowchart is given in Fig. 6 to summarize our retrieval method. First, the conditional PDF, describing the RR-P relationship, is specified by simulated attenuation indices from 3D cloud-resolving and radiative transfer models. Second, the prior RR distribution is specified by TRMM/PR data. Then, based on the Bayes' theorem, we calculate the posterior RR distribution that is a normalized product of the conditional and prior distributions. Once the posterior distribution is known, two common estimators are used to build three-dimensional lookup tables for retrieval of each pixel. These estimators are the average and the maximum of a posterior probability, denoted as Baye_AVE and Baye_MAP, respectively, and stored in lookup tables for various $P$ values with an interval of 0.02 .

\section{VALIDATION}

\subsection{Rain Gauge}

We validate $R R$ retrievals against rain gauge measurements. These rain gauges, supported by the Japanese Meteorological Agency (JMA), are on 11 Japanese islands located around $220 \mathrm{~km}$ east of Taiwan and $300 \mathrm{~km}$ southwest of Okinawa (Table 1; Fig. 7). These gauges measure rainfall every $10 \mathrm{~min}$.

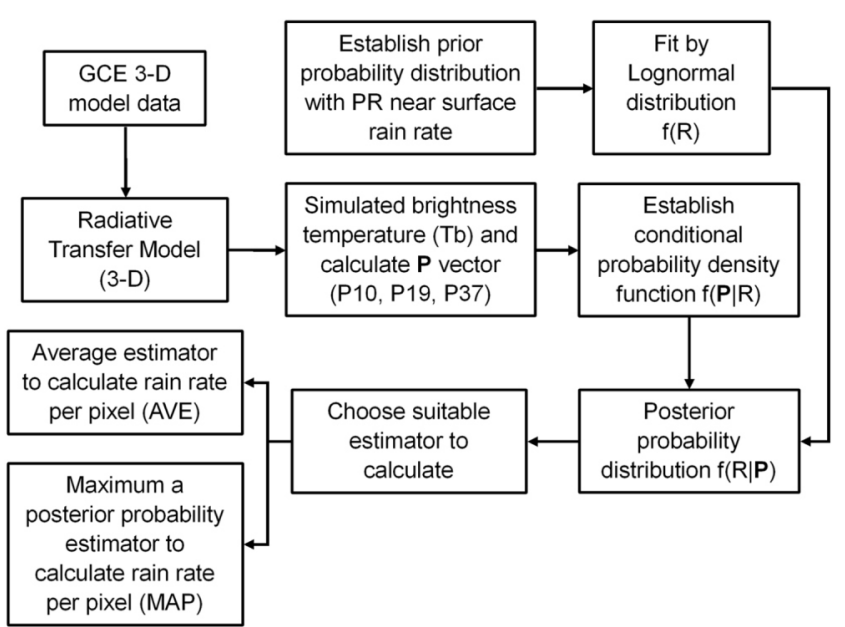

Fig. 6. The flowchart of Bayesian method for retrieving surface RR of typhoons over ocean. 
Table 1. The locations of rain gauges on isolated islands in Japan.

\begin{tabular}{clccc}
\hline No. & Rain gauge & Station No. & Location & Altitude (m) \\
\hline 1. & IRABU & 93011 & $24.82^{\circ} \mathrm{N}, 125.17^{\circ} \mathrm{E}$ & 10 \\
2. & MIYAKOJIMA & 93041 & $24.79^{\circ} \mathrm{N}, 125.27^{\circ} \mathrm{E}$ & 40 \\
3. & GUSUKUBE & 93051 & $24.74^{\circ} \mathrm{N}, 125.41^{\circ} \mathrm{E}$ & 55 \\
4. & TARAMA & 93061 & $24.66^{\circ} \mathrm{N}, 124.69^{\circ} \mathrm{E}$ & 16 \\
5. & IBARUMA & 94001 & $24.50^{\circ} \mathrm{N}, 124.28^{\circ} \mathrm{E}$ & 15 \\
6. & KABIRA & 94036 & $24.46^{\circ} \mathrm{N}, 124.14^{\circ} \mathrm{E}$ & 7 \\
7. & YONAGUNIJIMA & 94017 & $24.46^{\circ} \mathrm{N}, 123.01^{\circ} \mathrm{E}$ & 30 \\
8. & IRIOMOTEJIMA & 94061 & $24.38^{\circ} \mathrm{N}, 123.74^{\circ} \mathrm{E}$ & 9 \\
9. & ISHIGAKIJIMA & 94081 & $24.33^{\circ} \mathrm{N}, 124.16^{\circ} \mathrm{E}$ & 6 \\
10. & OOHARA & 94101 & $24.26^{\circ} \mathrm{N}, 123.87^{\circ} \mathrm{E}$ & 28 \\
11. & HATERUMA & 94116 & $24.05^{\circ} \mathrm{N}, 123.76^{\circ} \mathrm{E}$ & 38 \\
\hline
\end{tabular}

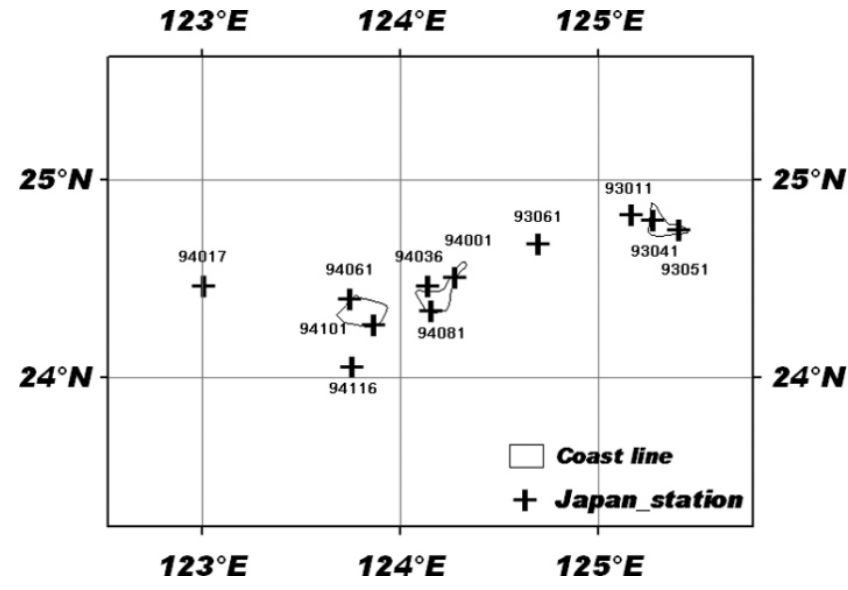

Fig. 7. A map of the 11 Japanese rain gauge stations.

The comparison of satellite RR retrievals with rain gauge observations can be challenging, though. This problem arises because satellite RR represents an average estimation in a FOV, while a rain gauge provides a point value measurement. In addition, satellite RR is retrieved from column-integrated microwave signatures that are affected by rain and ice particles aloft and thus may not be correlated well to surface RR. Because of these issues, Liu et al. (2001) analyzed two-year co-located ground-based microwave radiometry and rain gauge data, and suggested that a time period of 1 hour was optimal for comparing satellite retrievals and surface RRs. This optimal time period was also found to be the same by Chen and Li (2002). Therefore, to obtain the best correlation in our comparison for all retrieval methods (see next section), for each rain gauge, we calculate rain rate using gauge measurements over a time window that is 30 minutes prior to and after the satellite overpass.

\subsection{Benchmark Algorithm}

Two benchmark algorithms are used to evaluate the performance of the new RR retrieval method presented here. One is GPROF that is the official algorithm for TMI; the other is a statistical algorithm derived by multi-channel linear regressive statistical method (MLRS; Chen and Li 2002). GPROF is a Bayesian algorithm (Kummerow et al. 1996, 2001; Olson et al. 2006) and used to produce TRMM standard 2A12 product. This algorithm introduces a database to represent the prior PDFs of rain rate and cloud profiles, using simulations of hurricanes, squall lines, and mid-latitude cyclones. Cloud profiles are selected when their corresponding microwave brightness temperatures are close to the observed values. The selected cloud profiles are then averaged to yield the best surface rain rate and precipitation structure for each pixel.

DeMoss and Bowman (2007) reported that TMI 2A12 retrievals (version 6 ) are biased around $12 \%$ and $1 \%$ low relative to rain gauges during the pre-boost and post-boost periods, respectively. As we will show later, the typhoon cases studied in this paper occurred in the post-boost period. Compared to the reported global low bias of $1 \%$, it would be interesting to learn whether TMI $2 \mathrm{~A} 12$ products perform differently for extremely heavy rain events. Note that $2 \mathrm{~A} 12$ products provide surface rain rate at a resolution of $5 \mathrm{~km}$. To match the resolution of our retrievals, we averaged surface rain rates of $2 \mathrm{~A} 12$ (version 6) to $10 \mathrm{~km}$ for intercomparison.

The second benchmark algorithm is derived by multichannel linear regression statistical method. Recall that microwave brightness temperatures have a non-monotonic relationship with RR (see section 2). Microwave brightness temperatures respond mostly to emission from cloud and liquid rain at lower RRs, and mostly to scattering from ice 
particles at higher RRs. Therefore, our statistical method, similar to Chen and $\mathrm{Li}$ (2002), uses two regression equations to describe these two regimes separately. We call this statistical method as MLRS hereafter.

Regressions were generated using a match-up data set of rain gauge measurements and TMI overpasses from 1998 2003. Rain gauges used in regression analysis are the same as those in retrieval validation (Table 1). A total of 14 typhoon cases ( 64 overpasses) were selected. When $\mathrm{TB}_{85 \mathrm{~V}}$ and $\mathrm{TB}_{85 \mathrm{H}}$ are lower than 274.56 and $253.61 \mathrm{~K}$, respectively, we determine that the data point is in the scattering regime and its equation of RR can be approximated by:

$$
\begin{aligned}
R= & 152.65-0.77 \mathrm{~TB}_{10 \mathrm{~V}}+0.47 \mathrm{~TB}_{10 \mathrm{H}}-0.147 \mathrm{~TB}_{19 \mathrm{~V}} \\
& +0.537 \mathrm{~TB}_{19 \mathrm{H}}-0.508 \mathrm{~TB}_{21 \mathrm{~V}}+0.818 \mathrm{~TB}_{37 \mathrm{~V}} \\
& -0.773 \mathrm{~TB}_{37 \mathrm{H}}-0.91 \mathrm{~TB}_{85 \mathrm{~V}}+0.803 \mathrm{~TB}_{85 \mathrm{H}}
\end{aligned}
$$

Otherwise, the data point is in the emission regime, and the regression equation is given as:

$$
\begin{aligned}
R= & -44.28-0.107 \mathrm{~TB}_{10 \mathrm{~V}}+0.06 \mathrm{~TB}_{10 \mathrm{H}}+0.7 \mathrm{~TB}_{19 \mathrm{~V}} \\
& -0.15 \mathrm{~TB}_{19 \mathrm{H}}-0.308 \mathrm{~TB}_{21 \mathrm{~V}}+0.148 \mathrm{~TB}_{37 \mathrm{~V}} \\
& -0.15 \mathrm{~TB}_{37 \mathrm{H}}-0.17 \mathrm{~TB}_{85 \mathrm{~V}}+0.18 \mathrm{~TB}_{85 \mathrm{H}}
\end{aligned}
$$

Note that for this method, we screened rain and no rain as follows. Based on our match-up data, a pixel is determined as possibly rainy when observed $\mathrm{TB}_{10 \mathrm{~V}}, \mathrm{~TB}_{10 \mathrm{H}}, \mathrm{TB}_{19 \mathrm{~V}}, \mathrm{~TB}_{19 \mathrm{H}}$, and $\mathrm{TB}_{21 \mathrm{~V}}$ are greater than $174.83,91.54,213.77,153.46$, and $241.54 \mathrm{~K}$, respectively. Then, if the pixel has a scattering index (SI; Ferraro et al. 1994) greater than 10, it is assigned as a rainy pixel. Otherwise, the pixel is rain-free.

\subsection{Results of Intercomparison}

Retrieved RR is validated from qualitative and quantitative aspects. First, we present qualitative comparison of horizontal structures from two overpasses of Typhoon Aere. This comparison was conducted mainly against PR-retrieved RR. Second, we present quantitative comparisons against rain gauge measurements for 5 typhoon cases (16 overpasses) in 2004 (Table 2).

Figure 8 shows the track of slow-moving (about 12 $15 \mathrm{~km} \mathrm{hr}^{-1}$ ) Typhoon Aere that originated east of the Philippines on 20 August 2004. On August 24, the typhoon passed over Miyako and Yaeyama Islands. It had a peak intensity of $\sim 45 \mathrm{~m} \mathrm{~s}^{-1}$, low pressure of $955 \mathrm{hPa}$, and a wide eye of $80 \mathrm{~km}$. Typhoon Aere struck Taiwan on August 25. Some parts of Taiwan recorded accumulated rainfalls of 1.5 meters.

Figure 9 shows retrieved RR distributions of Typhoon Aere from PR, the new retrieval method (Baye_AVE and Baye_MAP), GPROF, and MLRS. For visualization purposes, the projection of PR RRs on the horizontal plane is also provided in Fig. 9b. The projection is plotted only when the corresponding PR surface RR is greater than $10 \mathrm{~mm} \mathrm{hr}^{-1}$. In Fig. 9a of the PR rain map, the eye of Typhoon AERE is at around $\left(25^{\circ} \mathrm{N}, 124^{\circ} \mathrm{E}\right)$. Two narrow rain bands are seen around the eye and $126^{\circ} \mathrm{E}$. Between two rain bands, there is an area $\left(\sim 125.5^{\circ} \mathrm{E}\right)$ with no rain or very light rain rates. Figures $9 \mathrm{c}-\mathrm{f}$ show that the locations of the eye and rain bands in retrieved precipitation distributions are similar to what have been found in the PR rain map, although retrieved rain rates from the aforementioned methods are quite dif-

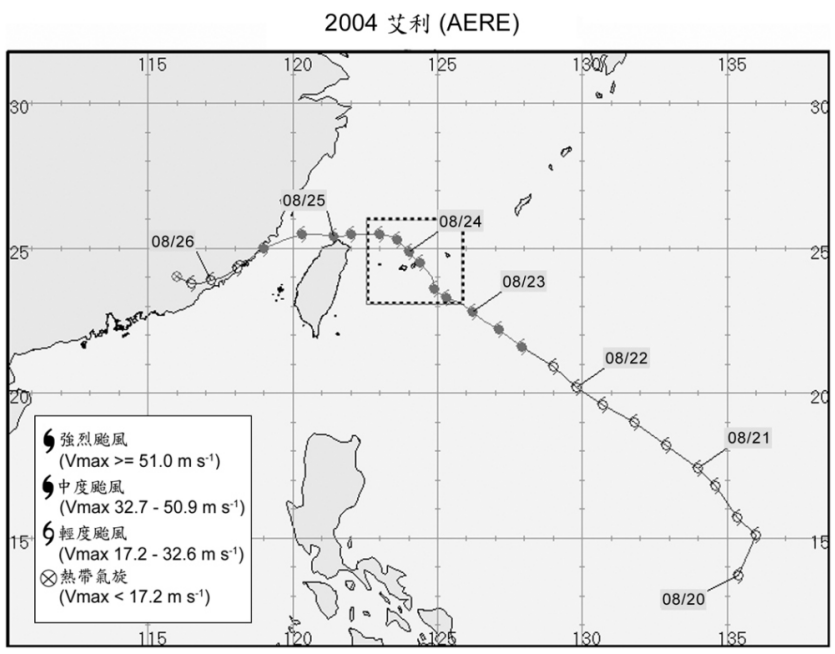

Fig. 8. The best track of Typhoon Aere originating east of the Philippines on 20 August 2004 (by courtesy of Central Weather Bureau). The inner dashed box corresponds to the domain shown in Fig. 7.

Table 2. Five typhoon cases for validating rain rate retrievals against rain gauge measurements.

\begin{tabular}{clcccc}
\hline No. & Name of Typhoon & Time of data & Max. wind speed $\left(\mathbf{m ~ s}^{-1}\right)$ & Pressure (hPa) & No. of Overpass \\
\hline 1 & CONSON & $20040609 \sim 0610$ & 47 & 960 & 2 \\
2 & MINDULLE & $20040701 \sim 0703$ & 62 & 940 & 4 \\
3 & AERE & $20040823 \sim 0825$ & 42 & 955 & 5 \\
4 & HAIMA & $20040911 \sim 0912$ & 15 & 992 & 4 \\
5 & NOCK-TEN & $20041025 \sim 1026$ & 55 & 945 & 1 \\
\hline
\end{tabular}




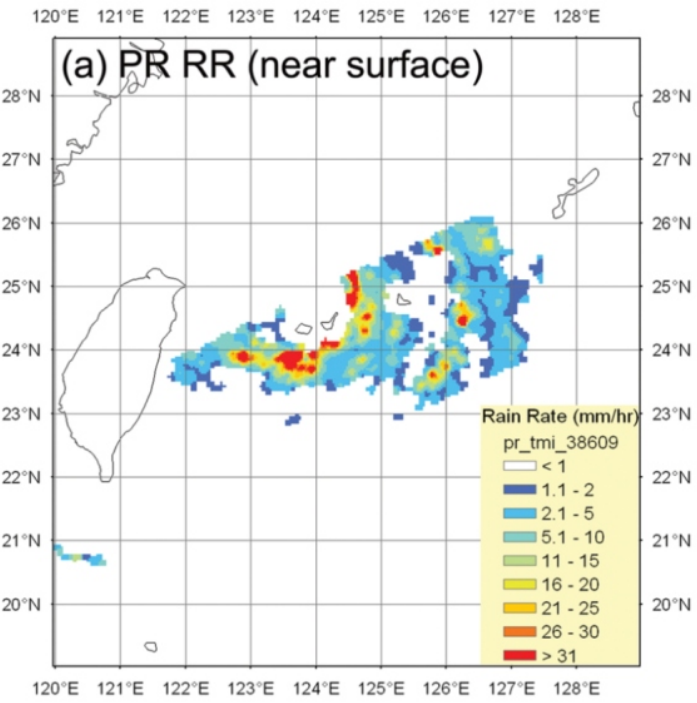

$\quad 120^{\circ} \mathrm{E} \quad 121^{\circ} \mathrm{E} \quad 122^{\circ} \mathrm{E} \quad 123^{\circ} \mathrm{E} \quad 124^{\circ} \mathrm{E} \quad 125^{\circ} \mathrm{E} \quad 126^{\circ} \mathrm{E} \quad 127^{\circ} \mathrm{E} \quad 128^{\circ} \mathrm{E}$

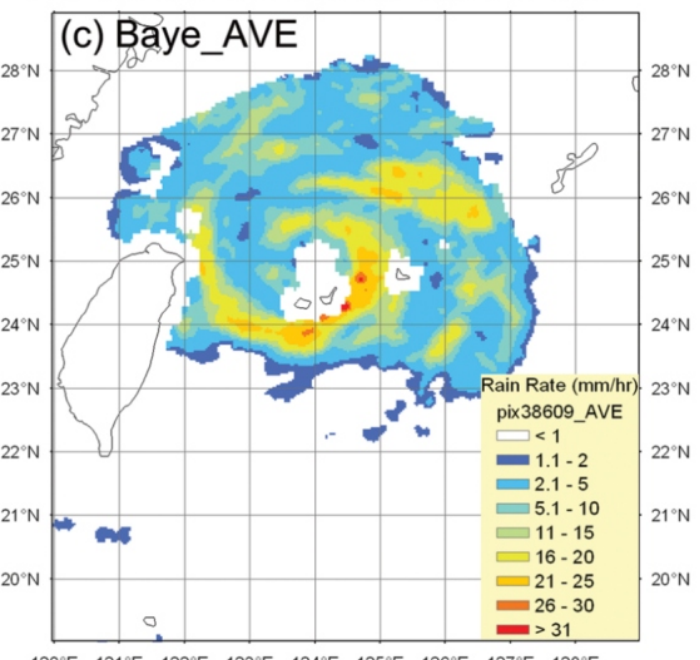

$120^{\circ} \mathrm{E} \quad 121^{\circ} \mathrm{E} \quad 122^{\circ} \mathrm{E} \quad 123^{\circ} \mathrm{E} \quad 124^{\circ} \mathrm{E} \quad 125^{\circ} \mathrm{E} \quad 126^{\circ} \mathrm{E} \quad 127^{\circ} \mathrm{E} \quad 128^{\circ} \mathrm{E}$

\section{(e) GPROF}

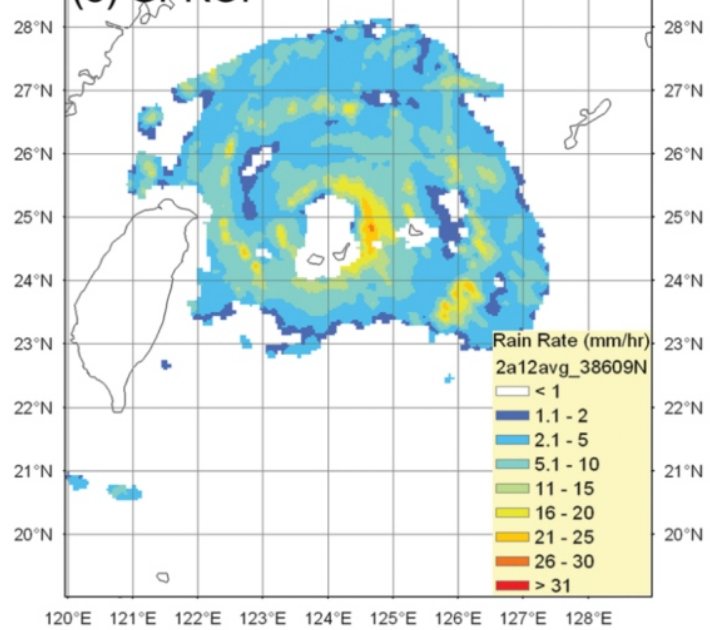

(b) 3D PR RR (vertical profile)

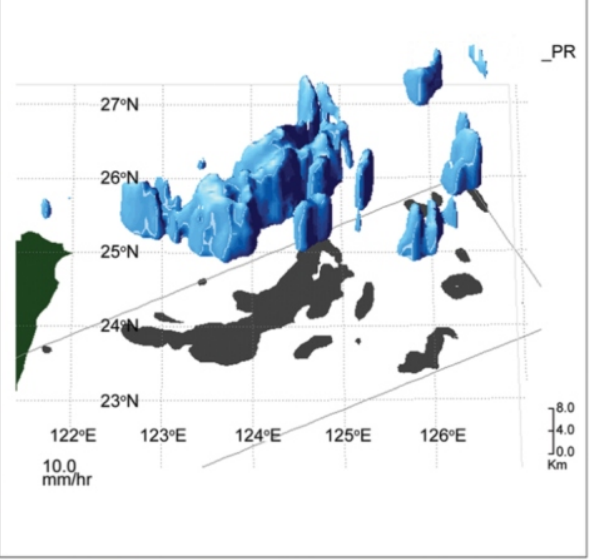

$120^{\circ} \mathrm{E} \quad 121^{\circ} \mathrm{E} \quad 122^{\circ} \mathrm{E} \quad 123^{\circ} \mathrm{E} \quad 124^{\circ} \mathrm{E} \quad 125^{\circ} \mathrm{E} \quad 126^{\circ} \mathrm{E} \quad 127^{\circ} \mathrm{E} \quad 128^{\circ} \mathrm{E}$

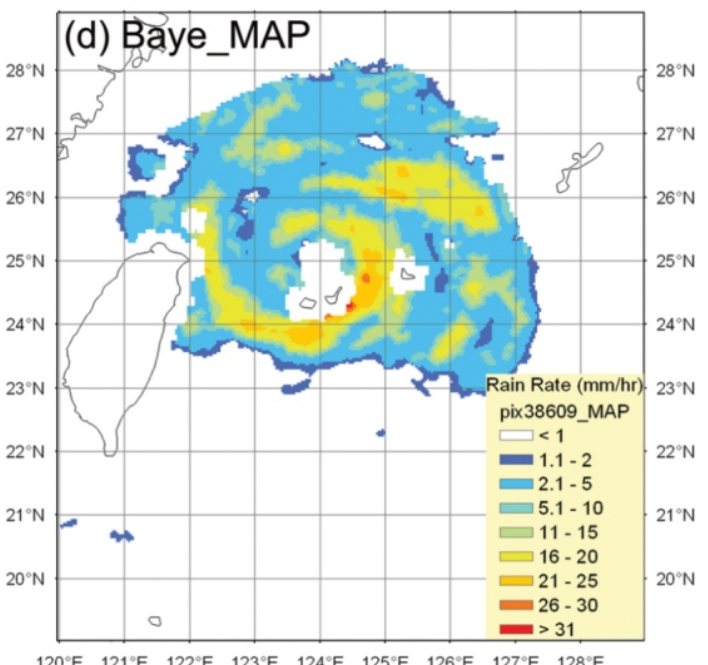

$120^{\circ} \mathrm{E} \quad 121^{\circ} \mathrm{E} \quad 122^{\circ} \mathrm{E} \quad 123^{\circ} \mathrm{E} \quad 124^{\circ} \mathrm{E} \quad 125^{\circ} \mathrm{E} \quad 126^{\circ} \mathrm{E} \quad 127^{\circ} \mathrm{E} \quad 128^{\circ} \mathrm{E}$

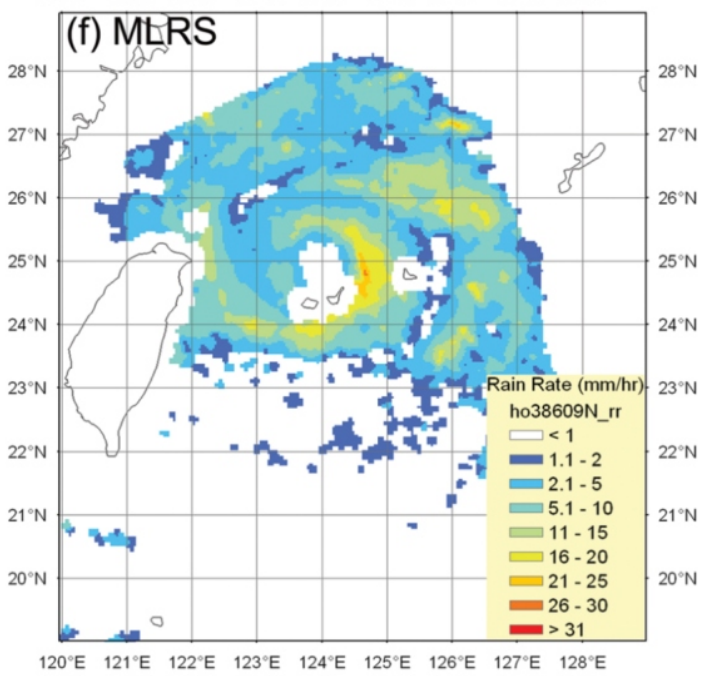

Fig. 9. Rain rates (a) and 3D vertical profiles (b) of Typhoon Aere retrieved from PR for orbit No. 38609 at 0151 UTC on 24 August 2004. In (b), we also shade areas that correspond to PR surface rain rate greater than $10 \mathrm{~mm} \mathrm{hr}^{-1}$. Rain rates in (a) are compared to those retrieved from (c) Baye_AVE, (d) Baye_MAP, (e) the Goddard Profiling Algorithm (GPROF), and (f) a multi-channel linear regression statistical method (MLRS). Baye_AVE and Baye_MAP are both derived from our Bayesian method, representing the average and the maximum value of the posterior probability, respectively. 
ferent. For the rain bands, PR RRs are in better agreement with retrievals from Baye_AVE and Baye_MAP than those from GPROF and MLRS. For the area between rain bands, MLRS seems to perform best, and Baye_AVE and Baye MAP tend to overestimate RRs. Figure 10 takes a closer look at one of the rain bands around the eye wall. This figure confirms that Baye_AVE and MLRS capture the main inner rain band, while the rain band from GPROF is not well defined in the south of the eye. On the other hand, GPROF and MLRS capture light rain areas better than Baye_AVE. We also found similar results in another overpass for Typhoon AERE (Fig. 11): two bands with heavy rain rates are seen both in the PR rain map and in Baye_AVE retrievals, but are less dis- tinct in retrievals of GPROF and MLRS. However, clearly, Baye_AVE overestimates rain rates in the area of $\left(24^{\circ} \mathrm{N}\right.$, $\left.124^{\circ} \mathrm{E}\right)$. To better understand whether any bias exists in our retrievals, quantitative comparisons are conducted next.

In our quantitative validation against rain gauge measurements, we exclude two types of TMI pixels. First, we exclude pixels that are associated with significant beam filling effects (Kummerow 1998), because for those pixels, rain gauges measurements might be too localized to compare with TMI retrievals. The homogeneity of precipitation for each TMI pixel was evaluated by examining infrared brightness temperatures at $11-\mu \mathrm{m}$ from the Visible Infrared Scanner (VIRS) of TRMM. Typically within a TMI FOV, there
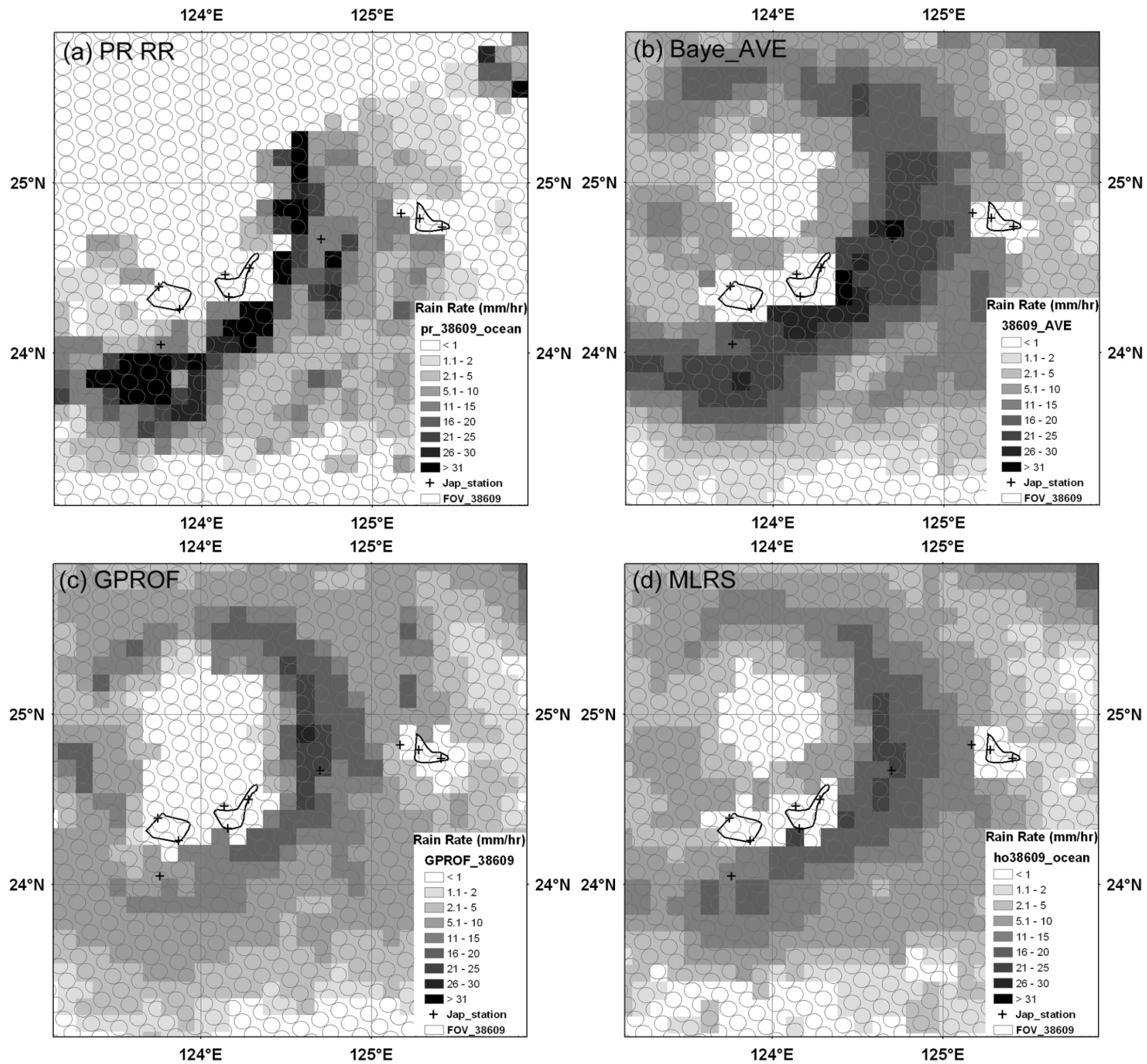

Fig. 10. A zoom-in of Fig. 8. Rain rates are retrieved from (a) PR RR, (b) Baye_AVE, (c) GPROF, and (d) MLRS. Plus signs (“+”) represent locations of rain gauges, while solid lines are coastlines. Underlying circles (“○”) represent TMI FOV. 

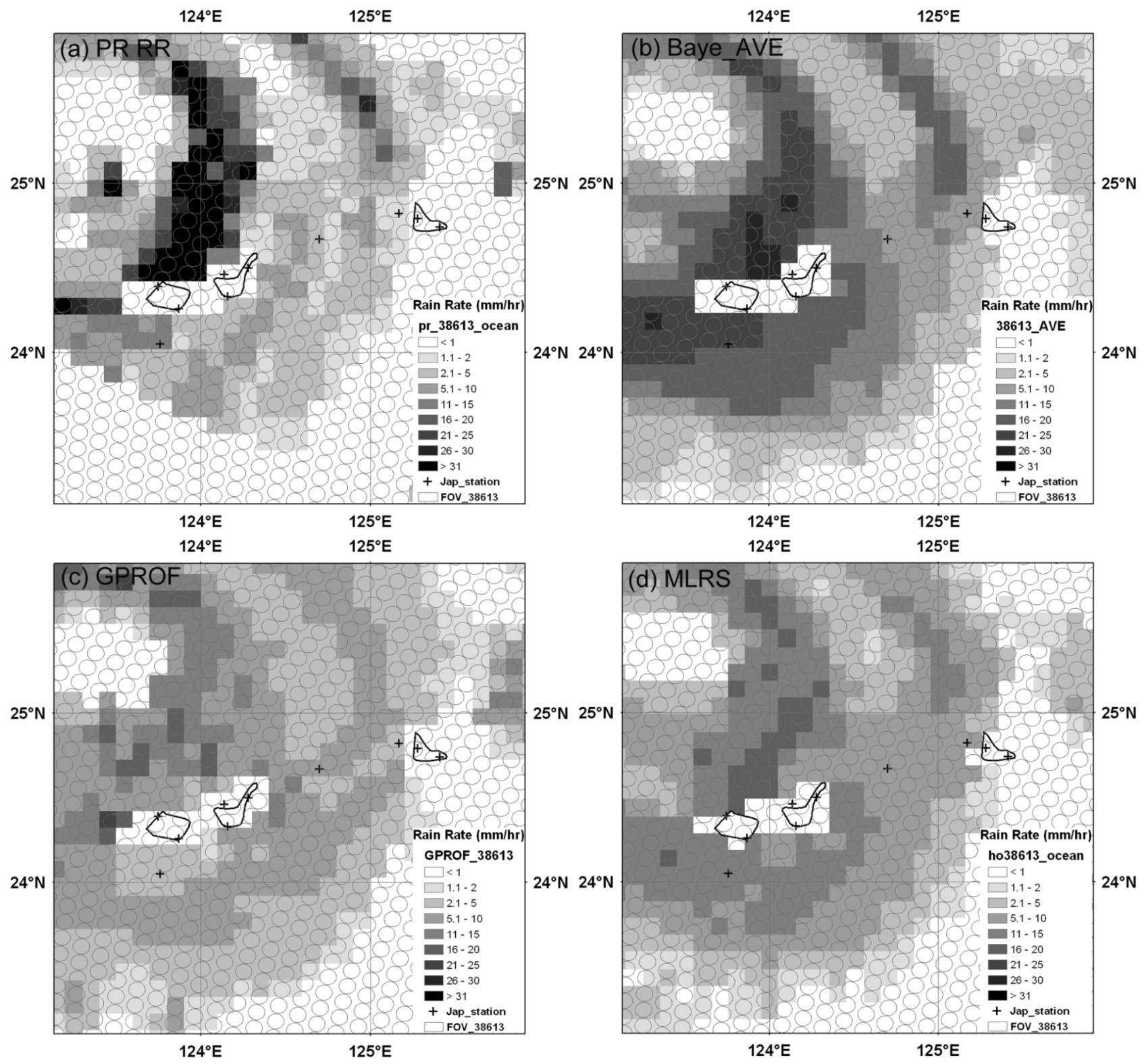

Fig. 11. Same as Fig. 10, but for Orbit No. 38613 that Typhoon Aere passed at 0826 UTC on 24 August 2004.

are around 15 VIRS pixels. If the standard deviation of brightness temperatures of these VIRS pixels is greater than $8 \mathrm{~K}$, following Chen and Li (2002), we determine that the beam filling effect is significant and exclude the TMI pixel in our comparison.

Second, we exclude pixels that are affected by high emissivity of land. TMI pixels are categorized as either land, coast, or oceanic, based on a high-resolution $(100 \mathrm{~m})$ geographic database from ArcGIS. If a pixel is defined as land or coast, the observed microwave brightness temperatures are most likely affected by land emissivity, and thus we cannot estimate the RR using our oceanic retrieval method. Therefore, if a rain gauge is found to be co-located with a land or coast TMI pixel, we use retrievals from the nearest oceanic TMI pixel to compare with rain gauge measurements.

Five typhoons in 2004 (Table 2) were used in our quantitative validations. After excluding pixels affected by beamfilling effect or/and land contamination, only 28 out of 66 match-up pixels are left in our comparisons. Figure 12 shows scatter plots of retrieved RR versus rain gauge measurements. The coefficients of determination (R2; Garrett and Woodworth 1960) and root-mean-squared error (RMS) are also listed for each retrieval method. These plots demonstrate that retrievals from the Baye_AVE method have the best linearity and the smallest RMS against rain gauge data. Comparing Fig. 12a with $\mathrm{b}$, we have found that the Baye MAP method has better performance than Baye_AVE at RR less than $5 \mathrm{~mm} \mathrm{hr}^{-1}$, but tends to underestimate $\mathrm{RR}$ in the 

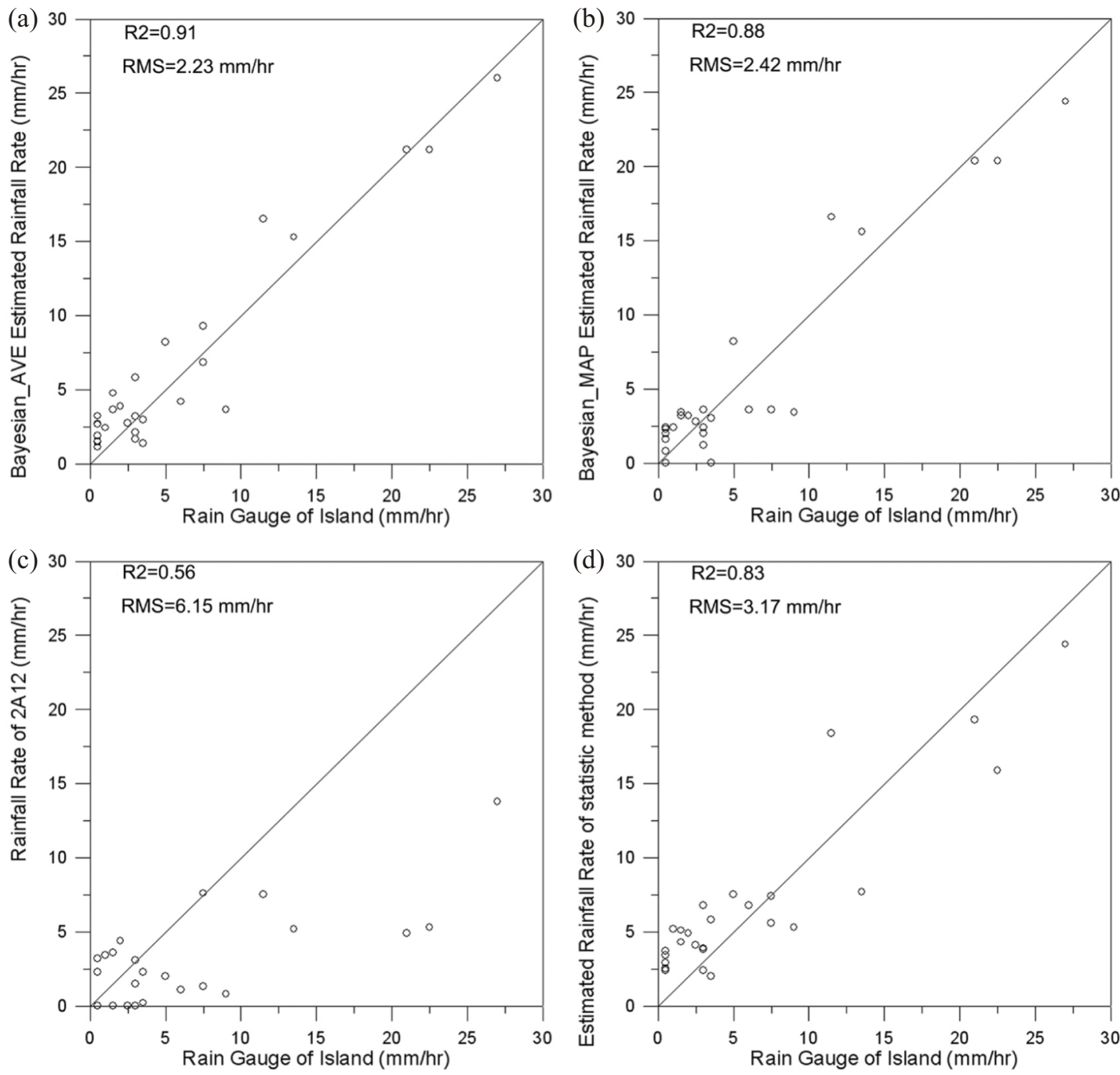

Fig. 12. Scatter plots of retrieved rain rate versus rain gauge measurements. Rain rate is retrieved from the (a) Baye_AVE, (b) Baye_MAP, (c) GPROF, and (d) MLRS method. Coefficients of determination (R2) and root-mean-square errors (RMS) are also shown here.

range between 5 and $10 \mathrm{~mm} \mathrm{hr}^{-1}$. The GPROF method (Fig. 12c) has significant errors for RRs higher than $5 \mathrm{~mm} \mathrm{hr}^{-1}$. Retrievals from the MLRS method (Fig. 12d) have good linearity against rain gauge data, but scatter more significantly than those retrieved from Baye_AVE, especially at RRs greater than $10 \mathrm{~mm} \mathrm{hr}^{-1}$. In addition, the MLRS method tends to overestimate in light RR regimes and underestimate in heavy RR regimes, which is a typical drawback for a linear statistical retrieval method.

\section{CONCLUSION}

We developed a new Bayesian approach to retrieve oceanic RR from TRMM/TMI microwave brightness temperatures, with an emphasis on typhoon cases in the West Pacific. The success of a Bayesian retrieval method relies on two factors: one is the prior distribution about RR, and the other is the conditional probability distribution that describes how microwave observations respond to RR. In this paper, we specified the prior distribution using retrievals of TRMM PR, while the dependency of microwave observations on RR was based on simulations of cloud-resolving and $3 \mathrm{D}$ radiative transfer models.

Simulations used to build conditional probabilities were squall line cases in the KWAJEX. The rationale for the use of this experiment is that large scale forcing was well provided for in the cloud-resolving model, and extensive evaluations have been conducted. Comparing our simulated microwave brightness temperatures with TMI observations, we showed that simulations and observations have similar statistics, although they are not similar in horizontal structures of rain clouds. We also found that the cloud model generated more data points with heavy rain rates that were not frequently sampled by TMI observations.

We used an attenuation index as the observed variable in our method. Unlike brightness temperature, attenuation in- 
dex has a monotonic relationship with RR, and is less sensitive to background noise from water vapor, wind speed and sea surface temperature. In addition, because the attenuation index at $85 \mathrm{GHz}$ approaches zero at small RRs $\left(\sim 1 \mathrm{~mm} \mathrm{hr}^{-1}\right)$, we used indices at $10.65,19.35$, and $37.0 \mathrm{GHz}$ that are not saturated at higher RR for typhoon cases. Note that an excess of frozen hydrometeor concentration in cloud model simulation has been reported in many cases (Zhou et al. 2007; Zeng et al. 2008), leading to significant scattering signatures at higher frequencies. Therefore, the use of an attenuation index at lower frequencies also helps to reduce uncertainty from unrealistic frozen hydrometeors in simulations.

Validations of our new Bayesian approach were conducted against retrievals from PR, GPROF, and MLRS methods, and measurements from rain gauges located on Japanese islands. Fifteen typhoons that passed over rain gauges in 2004 were selected. We found that our Bayesian retrievals and PR RR show significant similarity in horizontal distributions of precipitation. Quantitative results also demonstrate that our retrievals agree well with rain gauge measurements, showing the highest correlation (0.95) and the smallest root-mean squared error $\left(\sim 2 \mathrm{~mm} \mathrm{hr}^{-1}\right)$.

This paper demonstrates that our new method provides satisfactory RR retrievals for typhoon cases over the ocean, which could help analyze structures of tropical cyclones, improve model initialization, and predict storm tracks and potential landfall. It is desired to include more typhoon simulations in our database and to investigate how much extra information could be added in. We have started simulations using the Weather Research and Forecasting (WRF) model. More regional and global validations in simulations and retrievals are part of our ongoing research.

Acknowledgements This research was supported by NSC 95-2625-Z-014-002. We would like to thank Prof. Guosheng Liu for his 3D forward radiative transfer model and helpful discussions. We would also like to thank Drs. Chung-Lin Shie and Wei-Kuo Tao for their GCE model simulations and valuable comments. Special thanks to the US Tropical Rainfall Measuring Mission office for TMI, 2A12-GPROF, and 2A25-PR data.

\section{REFERENCES}

Adler, R. F., C. Kidd, G. Petty, M. Morrissey, and H. M. Goodman, 2001: Intercomparison of global precipitation products: The Third Precipitation Intercomparison Project (PIP-3). Bull. Amer. Meteor. Soc., 82, 1377-1396, doi: 10.1175/1520-0477(2001)082<1377:IOGPPT>2.3.CO;2. [Link]

Atlas, R., A. Y. Hou, and O. Reale, 2005: Application of SeaWinds scatterometer and TMI-SSM/I rain rates to hurricane analysis and forecasting. J. Photogrammetry Remote Sens., 59, 233-243, doi: 10.1016/j.isprsjprs.2005. 02.007. [Link]
Benedetti, A., P. Lopez, E. Moreau, P. Bauer, and V. Venugopal, 2005: Verification of TMI-adjusted rainfall analyses of tropical cyclones at ECMWF using TRMM precipitation radar. J. Appl. Meteorol., 44, 1677-1690, doi: 10.1175/ JAM2300.1. [Link]

Bowman, K. P., 2005: Comparison of TRMM precipitation retrievals with rain gauge data from ocean buoys. J. Climate, 18, 178-190, doi: 10.1175/JCLI3259.1. [Link]

Chen, W.-J. and C.-C. Li, 2002: Rain retrievals using Tropical Rainfall Measuring Mission and geostationary meteorological satellite 5 data obtained during the SCSMEX. Int. J. Remote Sens., 23, 2425-2448, doi: 10.1080/014311601 10075884. [Link]

Chiu, J. C., 2003: Bayesian retrieval of complete posterior PDFs of rain rate from satellite passive microwave observations. Ph.D. Thesis, Purdue University, USA, 174 pp.

Chiu, J. C. and G. W. Petty, 2006: Bayesian retrieval of complete posterior PDFs of oceanic rain rate from microwave observations. J. Appl. Meteorol. Climatol., 45, 1073-1095, doi: 10.1175/JAM2392.1. [Link]

Cho, H.-K., K. P. Bowman, and G. R. North, 2004: A comparison of gamma and lognormal distributions for characterizing satellite rain rates from the Tropical Rainfall Measuring Mission. J. Appl. Meteorol., 43, 1586-1597, doi: 10.1175/JAM2165.1. [Link]

DeMoss, J. D. and K. P. Bowman, 2007: Changes in TRMM rainfall due to the orbit boost estimated from buoy rain gauge data. J. Atmos. Ocean. Technol., 24, 1598-1607, doi: 10.1175/JTECH2082.1. [Link]

Di Michele, S., A. Tassa, A. Mugnai, F. S. Marzano, P. Bauer, and J. P. V. P. Baptista, 2005: Bayesian algorithm for microwave-based precipitation retrieval: Description and application to TMI measurements over ocean. IEEE Trans. Geosci. Remote Sensing, 43, 778-791, doi: 10.1109/ TGRS.2005.844726. [Link]

Evans, K. F., J. Turk, T. Wong, and G. L. Stephens, 1995: A Bayesian approach to microwave precipitation profile retrieval. J. Appl. Meteorol., 34, 260-279.

Ferraro, R. R., N. Grody, and G. F. Marks, 1994: Effects of surface conditions on rain identification using the DMSPSSM/I. Remote Sens. Rev., 11, 195-209.

Garrett, H. E. and R. S. Woodworth, 1960: Statistics in Psychology and Education, Longmans, Green and Co., 478 pp.

Grecu, M. and W. S. Olson, 2006: Bayesian estimation of precipitation from satellite passive microwave observations using combined radar-radiometer retrievals. J. Appl. Meteorol. Climatol., 45, 416-433, doi: 10.1175/JAM2360.1. [Link]

Hou, A. Y., S. Q. Zhang, A. M. da Silva, W. S. Olson, C. D. Kummerow, and J. Simpson, 2001: Improving global analysis and short-range forecast using rainfall and moisture observations derived from TRMM and SSM/I passive microwave sensors. Bull. Amer. Meteor. Soc., 82, 659-679, doi: 10.1175/1520-0477(2001)082<0659:IGAASF>2.3. CO;2. [Link] 
Hou, A. Y., S. Q. Zhang, and O. Reale, 2004: Variational continuous assimilation of TMI and SSM/I rain rates: Impact on GEOS-3 hurricane analyses and forecasts. Mon. Wea. Rev., 132, 2094-2109, doi: 10.1175/1520-0493(2004)132 $<2094$ :VCAOTA>2.0.CO;2. [Link]

Iguchi, T., T. Kozu, R. Meneghini, J. Awaka, and K. Okamoto, 2000: Rain-profiling algorithm for the TRMM precipitation radar. J. Appl. Meteorol., 39, 2038-2052, doi: 10.1175/ 1520-0450(2001)040<2038:RPAFTT >2.0.CO;2. [Link]

Kedem, B., L. S. Chiu, and G. R. North, 1990: Estimation of mean rain rate: Application to satellite observations. $J$. Geophys. Res., 95, 1965-1972, doi: 10.1029/JD095iD02 p01965. [Link]

Krishnamurti, T. N., S. Surendran, D. W. Shin, R. J. CorreaTorres, T. S. V. V. Kumar, E. Williford, C. Kummerow, R. F. Adler, J. Simpson, R. Kakar, W. S. Olson, and F. J. Turk, 2001: Real-time multianalysis-multimodel superensemble forecasts of precipitation using TRMM and SSM/I products. Mon. Wea. Rev., 129, 2861-2883, doi: 10.1175/ 1520-0493(2001)129<2861:RTMMSF>2.0.CO;2. [Link]

Kummerow, C., 1998: Beam-filling errors in passive microwave rainfall retrievals. J. Appl. Meteorol., 37, 356-370, doi: 10.1175/1520-0450(1998)037<0356:BEIPMR>2.0. CO;2. [Link]

Kummerow, C., W. S. Olson, and L. Giglio, 1996: A simplified scheme for obtaining precipitation and vertical hydrometeor profiles from passive microwave sensors. IEEE Trans. Geosci. Remote Sens., 34, 1213-1232, doi: 10.1109/36.536538. [Link]

Kummerow, C., W. Barnes, T. Kozu, J. Shiue, and J. Simpson, 1998: The Tropical Rainfall Measuring Mission (TRMM) sensor package. J. Atmos. Ocean. Technol., 15, 809-817, doi: 10.1175/1520-0426(1998)015<0809:TTRMMT>2.0. CO;2. [Link]

Kummerow, J. Simpson, O. Thiele, W. Barnes, A. T. C. Chang, E. Stocker, R. F. Adler, A. Hou, R. Kakar, F. Wentz, P. Ashcroft, T. Kozu, Y. Hong, K. Okamoto, T. Iguchi, H. Kuroiwa, E. Im, Z. Haddad, G. Huffman, B. Ferrier, W. S. Olson, E. Zipser, E. A. Smith, T. T. Wilheit, G. North, T. Krishnamurti, and K. Nakamura, 2000: The status of the Tropical Rainfall Measuring Mission (TRMM) after two years in orbit. J. Appl. Meteorol., 39, 1965-1982, doi: 10.1175/1520-0450(2001)040<1965:TSOTTR >2.0.CO;2. [Link]

Kummerow, C., Y. Hong, W. S. Olson, S. Yang, R. F. Adler, J. McCollum, R. Ferraro, G. Petty, D. B. Shin, and T. T. Wilheit, 2001: The evolution of the Goddard profiling algorithm (GPROF) for rainfall estimation from passive microwave sensors. J. Appl. Meteorol., 40, 1801-1820, doi: 10.1175/1520-0450(2001)040<1801:TEOTGP $>2.0$. CO;2. [Link]

Lin, Y. L., R. D. Farley, and H. D. Orville, 1983: Bulk parameterization of the snow field in a cloud model. J. Appl. Meteorol., 22, 1065-1092, doi: 10.1175/1520-0450(1983) $022<1065$ :BPOTSF $>2.0$. CO;2. [Link]
Liu, G., 1998: A fast and Accurate Model for Microwave Radiance Calculations. J. Meteorol. Soc. Jpn., 76, 335-343.

Liu, G., 2004: Approximation of single scattering properties of ice and snow particles for high microwave frequencies. $J$. Atmos. Sci., 61, 2441-2456, doi: 10.1175/1520-0469(2004) $061<2441$ :AOSSPO>2.0.CO;2. [Link]

Liu, G. R., C. C. Liu, and T. H. Kuo, 2001: Rainfall intensity estimation by ground-based dual-frequency microwave radiometers. J. Appl. Meteorol., 40, 1035-1041, doi: 10.1175/1520-0450(2001)040<1035:RIEBGB >2.0.CO;2. [Link]

Marshall, J. S. and W. M. Palmer, 1948: The distribution of raindrops with size. J. Meteorol., 5, 165-166, doi: 10.1175/ 1520-0469(1948)005<0165:TDORWS >2.0.CO;2. [Link]

Marzano, F. S., E. Fionda, P. Ciotti, and A. Martellucci, 2002: Ground-based multifrequency microwave radiometry for rainfall remote sensing. IEEE Trans. Geosci. Remote Sens., 40, 742-759, doi: 10.1109/TGRS.2002.1006317. [Link]

Masunaga, H., T. Iguchi, R. Oki, and M. Kachi, 2002: Comparison of rainfall products derived from TRMM Microwave Imager and precipitation radar. J. Appl. Meteorol., 41, 849-862, doi: 10.1175/1520-0450(2002)041<0849: CORPDF $>2.0 . C O ; 2$. [Link]

McCabe, M. F., E. F. Wood, R. Wojcik, M. Pan, J. Sheffield, H. Gao, and H. Su, 2008: Hydrological consistency using multi-sensor remote sensing data for water and energy cycle studies. Remote Sens. Environ., 112, 430-444, doi: 10.1016/j.rse.2007.03.027. [Link]

Nesbitt, S. W., E. J. Zipser, and C. D. Kummerow, 2004: An examination of version-5 rainfall estimates from the TRMM microwave imager, precipitation radar, and rain gauges on global, regional, and storm scales. J. Appl. Meteorol., 43, 1016-1036, doi: 10.1175/1520-0450(2004)043<1016: AEOVRE $>2.0 . \mathrm{CO} ; 2$. [Link]

Nzeukou, A. and H. Sauvageot, 2002: Distribution of rainfall parameters near the coasts of France and Senegal. J. Appl. Meteorol., 41, 69-82, doi: 10.1175/1520-0450(2002)041 $<0069$ :DORPNT $>2.0 . \mathrm{CO} ; 2$. [Link]

Olson, W. S., C. D. Kummerow, G. M. Heymsfield, and L. Giglio, 1996: A method for combined passive-active microwave retrievals of cloud and precipitation profiles. $J$. Appl. Meteorol., 35, 1763-1789, doi: 10.1175/1520-0450 (1996)035<1763:AMFCPM>2.0.CO;2. [Link]

Olson, W. S., C. D. Kummerow, S. Yang, G. W. Petty, W. K. Tao, T. L. Bell, S. A. Braun, Y. Wang, S. E. Lang, D. E. Johnson, and C. Chiu, 2006: Precipitation and latent heating distributions from satellite passive microwave radiometry. Part I: Improved method and uncertainties. J. Appl. Meteorol. Climatol., 45, 702-720, doi: 10.1175/JAM2369.1. [Link]

Petty, G. W., 1994: Physical retrievals of over-ocean rain rate from multichannel microwave imagery. Part I: Theoretical characteristics of normalized polarization and scattering indices. Meteorol. Atmos. Phys., 54, 79-99, doi: 10.1007/ BF01030053. [Link] 
Petty, G. W. 2001: Physical and microwave radiative properties of precipitating clouds. Part I. Principal component analysis of observed multichannel microwave radiances in tropical stratiform rainfall. J. Appl. Meteorol., 40, 21052114, doi: 10.1175/1520-0450(2001)040<2105:PAMRPO> 2.0.CO;2. [Link]

Rutledge, S. A. and P. V. Hobbs, 1984: The mesoscale and microscale structure and organization of clouds and precipitation in midlatitude cyclones. XII: A diagnostic modeling study of precipitation development in narrow coldfrontal rainbands. J. Atmos. Sci., 41, 2949-2972, doi: 10.1175/1520-0469(1984)041<2949:TMAMSA>2.0.CO; 2. [Link]

Sauvageot, H., 1994: The probability density function of rain rate and the estimation of rainfall by area integrals. J. Appl. Meteorol., 33, 1255-1262, doi: 10.1175/1520-0450(1994) $033<1255$ :TPDFOR $>2.0 . \mathrm{CO} ; 2$. [Link]

Seo, E. K., G. Liu, W. K. Tao, and S. O. Han, 2007: Adaptation of a model-generated cloud database to satellite observations. Geophys. Res. Lett., 34, L03805, doi: 10.1029/2006 GL027857. [Link]

Serra, Y. and M. McPhaden, 2003: Multiple time- and spacescale comparisons of ATLAS buoy rain gauge measurements with TRMM satellite precipitation measurements. $J$. Appl. Meteorol., 42, 1045-1059, doi: 10.1175/1520-0450 (2003)042<1045:MTASCO>2.0.CO;2. [Link]

Shie, C. L., W. K. Tao, and J. Simpson, 2003: Simulated KWAJEX convective systems using a $2 \mathrm{D}$ and $3 \mathrm{D}$ cloud resolving model and their comparisons with radar observations, paper presented at $31^{\text {st }}$ Conference on Radar Meteorology. Am. Meteorol. Soc., Seattle, Wash.

Tao, W. K. and J. Simpson, 1989: Modeling study of a tropical squall-type convective line. J. Atmos. Sci., 46, 177-202, doi: 10.1175/1520-0469(1989)046<0177:MSOATS >2.0. CO;2. [Link]

Tao, W. K. and J. Simpson, 1993: Goddard cumulus ensemble model. Part I: Model description. Terr. Atmos. Ocean. Sci., 4, 35-72.

Tao, W. K., C. L. Shie, J. Simpson, S. Braun., R. H. Johnson, and P. E. Ciesielski, 2003: Convective systems over the South China Sea: Cloud-resolving model simulations. J. Atmos. Sci., 60, 2929-2956, doi: 10.1175/1520-0469(2003) 060<2929:CSOTSC $>2.0 . \mathrm{CO} ; 2$. [Link]

Treadon, R. E., 1996: Physical initialization in the NMC Global Data Assimilation System. Meteorol. Atmos. Phys., 60, 57-86, doi: 10.1007/BF01029786. [Link]

Wilheit, T. T., A. T. C. Chang, M. S. V. Rao, E. B. Rodgers, and J. S. Theon, 1977: A satellite technique for quantitatively mapping rainfall rates over the oceans, J. Appl. Meteorol., 16, 551-560, doi: 10.1175/1520-0450(1977)016<0551: ASTFQM $>2.0 . \mathrm{CO} ; 2$. [Link]

Zeng, X., W. K. Tao, S. Lang, A. Y. Hou, M. Zhang, and J. Simpson, 2008: On the sensitivity of atmospheric ensembles to cloud microphysics in long-term cloud-resolving model simulations. J. Meteorol. Soc. Jpn., 86, 45-65, doi: 10.2151/jmsj.86A.45. [Link]

Zhou, Y. P., W. K. Tao, A.Y. Hou, W. S. Olson, C. L. Shie, K. M. Lau, M. D. Chou, X. Lin, and M. Grecu, 2007: Use of high-resolution satellite observations to evaluate cloud and precipitation statistics from cloud-resolving model simulations. Part I: South China Sea monsoon experiment. J. Atmos. Sci., 64, 4309-4329, doi: 10.1175/2007JAS2281.1. [Link] 